\title{
Leukemia growth is inhibited by benzoxime without causing any harmful effect in rats bearing RBL-1 xenotransplants
}

\author{
YINGCHUN LI, HUIHAN WANG, RONG ZHANG, GUOJUN ZHANG, YING YANG and ZHUOGANG LIU \\ Department of Hematology, Shengjing Hospital, China Medical University, Shenyang, Liaoning 110021, P.R. China
}

Received December 13, 2017; Accepted July 16, 2018

DOI: $10.3892 / \mathrm{ol} .2018 .9783$

\begin{abstract}
The present study aimed to investigate the effect of benzoxime on leukemia RBL-1 cell proliferation and a leukemic Sprague-Dawley rat model. Proliferation of RBL-1 cells was determined using an MTT assay. Sprague-Dawley rats were assigned randomly into three groups of 10 animals each, where the positive control group was administered an intravenous injection of normal saline, the negative control group was administered $1 \times 10^{6}$ RBL-1 cells and the treatment group was administered with $1 \times 10^{6} \mathrm{RBL}-1$ cells and then benzoxime $(50 \mathrm{mg} / \mathrm{kg} / \mathrm{day})$ for 1 week. Increased dosage of benzoxime reduced RBL-1 cell viability from 92 at $2 \mu \mathrm{M}$ to $21 \%$ at $12 \mu \mathrm{M}$ after $24 \mathrm{~h}$. Benzoxime treatment prevented the loss of body weight in the rats with leukemia. Compared with the negative control rats, the body weight was determined to be significantly reduced $(\mathrm{P}<0.05)$ in the positive control rats. The weight of the spleen and liver was determined to be significantly increased $(\mathrm{P}<0.02)$ in the positive control rats and the benzoxime-treated rats compared with that in the negative control group on day 35 of RBL-1 cell implantation. Analysis of leukocytes in rats on day 35 demonstrated a significant reduction $(\mathrm{P}<0.05)$ in the cluster of differentiation $(\mathrm{CD}) 11 \mathrm{~b}$ and CD45 level in the positive control group compared with that in the negative control group. The level of CD11b and CD45 was determined to be similar in the rats in the benzoxime treatment and negative control groups. Analysis of the level of serum glutamic pyruvic transaminase, serum glutamic oxaloacetic transaminase and blood urea nitrogen indicated that all three components exhibited no significant changes in the rats following treatment with benzoxime compared with the component levels in the negative control group. The levels of these three components were in the normal range in rats treated with benzoxime on day 35 of cell implantation. These data demonstrated that the liver and kidneys are not influenced
\end{abstract}

Correspondence to: Professor Yingchun Li, Department of Hematology, Shengjing Hospital, China Medical University, 39 Huaxiang Road, Shenyang, Liaoning 110021, P.R. China

E-mail: lawskateliarmeh@yahoo.com

Key words: xenotransplant, pyruvic transaminase, leukocyte infiltration, surface marker by benzoxime in rats with leukemia. In summary, the present study demonstrated that benzoxime efficiently prevents leukemia growth without inducing any harmful effects in rat models through targeting CD11b and CD45 level; thus, benzoxime should be evaluated further regarding its use in the treatment of leukemia.

\section{Introduction}

Leukemia is one of the malignant clonal disease types involved with hematopoietic stem cells. In 2015 the incidence rate of leukemia was reported to be 5.68 cases/100,000 individuals in China (1). Leukemia is the leading cause of cancer-associated mortalities globally in children and adults $<35$ years old, and various studies have been conducted in order to understand its mechanisms (1-4). Leukemia is characterized by the upregulation of cell proliferation and its failure to undergo differentiation into hematopoietic cells (5-7). The treatment strategy for leukemia consists of transplantation of bone marrow, and chemo- and radiotherapy (8-10). Despite these available treatment strategies, leukemia continues to be the leading cause of mortality globally; therefore, clinicians and researchers require novel drug candidates in order to treat leukemia efficiently. Natural compounds isolated from diverse sources act as therapeutic candidates for the treatment and prevention of various disorders including cancer and arthritis (11-14). Natural products have been determined to act as neuroprotective, antioxidant (15), anti-inflammatory (16) and anti-apoptotic agents (17), as well as reducing autophagy (18). Sanguinarine is located in the plant Sanguinaria canadensis. Sanguinarine is a member of the alkaloid family and has been determined to act as a potential agent against inflammation, tumor growth and hypertension $(19,20)$.

The present study aimed to investigate the effect of benzoxime (Fig. 1) on RBL-1 leukemia cell proliferation and on leukemia Sprague-Dawley rat models. The results demonstrated that benzoxime treatment reduced RBL-1 leukemia cell proliferation in vitro and prevented damage to the spleen and liver, and changes in the biochemical profile of blood in vivo.

\section{Materials and methods}

Cell culture. The leukemia RBL-1 cell line was supplied by the Chinese Academy of Sciences (Shanghai, China). Cell culture was performed in $75-\mathrm{cm}^{2}$ tissue culture flasks, 
which contained RPMI-1640 medium (Gibco; Thermo Fisher Scientific, Inc., Waltham, MA, USA). L-glutamine (2 mM) and $10 \%$ fetal bovine serum were added to the medium (Gibco; Thermo Fisher Scientific, Inc.). The medium also contained $1 \%$ penicillin-streptomycin $(100 \mathrm{U} / \mathrm{ml}$ penicillin and $100 \mu \mathrm{g} / \mathrm{ml}$ streptomycin). The cells were incubated at $37^{\circ} \mathrm{C}$ in a humidified atmosphere of $5 \% \mathrm{CO}_{2}$.

Analysis of cell viability. The effect of benzoxime on leukemia RBL-1 cell viability was analyzed with an MTT assay. RBL-1 cells were seeded onto 96-well cell culture plates at a density of $2 \times 10^{4}$ cells/well and cultured for $24 \mathrm{~h}$. Benzoxime dissolved in dimethyl sulfoxide (DMSO) at 2-14 $\mu \mathrm{M}$ doses was added to the RPMI-1640 medium and incubation was conducted for $24 \mathrm{~h}$. The conditions for incubation used were a temperature of $37^{\circ} \mathrm{C}$ in an atmosphere containing $5 \% \mathrm{CO}_{2}$. Following incubation, the cells were washed twice with PBS and subsequently exposed to $0.5 \mathrm{mg} / \mathrm{ml}$ MTT. Incubation of the cells was continued for $4 \mathrm{~h}$ at $37^{\circ} \mathrm{C}$ and then the culture medium was removed. DMSO was added to the plates for solubilization of the formazan crystals. Measurement of the absorbance values for each plate was performed in triplicate independently at $485 \mathrm{~nm}$. The microplate autoreader (BioTek Instruments Inc., Winooski, VT, USA) was used for recording absorbance.

Handling of animals. The male Sprague-Dawley rats (8-week old; weight, 200 g; n=30) were purchased from the Guangzhou University's Laboratory Animal Center for Traditional Chinese Medicine [license no. scxk-129(Yue)2014-0129; Guangzhou, China]. The animals were accommodated under 12-h light and dark cycles in an animal house under conditions of controlled humidity and a temperature of $20^{\circ} \mathrm{C}$. The rats had free access to the fresh drinking water and standard laboratory diet ad libitum. The working protocols involving animals were approved by the Committee for Care and Use of Animal of Guangzhou University of Traditional Chinese Medicine (approval no. 2014A123).

Leukemia rat model development. The 30 Sprague-Dawley rats were randomly assigned into three groups of 10 animals each. To induce malignancy, $1 \times 10^{6} \mathrm{RBL}-1$ cells in $200 \mu \mathrm{l}$ sterile RPMI-1640 medium were inoculated subcutaneously into the postauricular region of the animals (18). The treatment group was inoculated with $1 \times 10^{6}$ RBL-1 cells subcutaneously and then treated with benzoxime $(50 \mathrm{mg} / \mathrm{kg} / \mathrm{day})$ for 1 week through an intravenous tail injection. The positive control group was administered with an intravenous injection of normal saline alone $(100 \mu \mathrm{l})$. The animals in negative control group were given $1 \times 10^{6}$ RBL-1 cells subcutaneously followed by administration of $100 \mu \mathrm{l}$ normal saline alone. During the study, the rat body weight was recorded every week. The animals were sacrificed on day 35 of the study using established $\mathrm{CO}_{2}$ euthanasia method where the flow rate of $\mathrm{CO}_{2}$ displaced $>30 \%$ of the chamber volume/minute, in order to extract the liver and spleen, and collect the blood samples. The liver and spleen of each animal was weighed as previously reported $(19,20)$. Tumor diameter was measured using calipers, and the tumor volume was calculated. The tumors were measured in 2 dimensions and tumor volume was calculated according to the formula $\mathrm{V}=\left(\mathrm{D} \mathrm{x} \mathrm{d}^{2}\right) / 2$, in which $\mathrm{D}$ and $\mathrm{d}$ are the major and minor perpendicular tumor diameters, respectively.

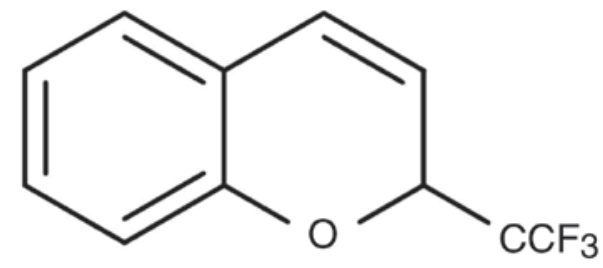

Figure 1. Chemical structure of benzoxime.

Immunofluorescence staining. The blood samples $(\sim 600 \mu \mathrm{l})$ from the rats were collected and then treated with lysing buffer (Pharm Lyse; BD Biosciences, San Jose, CA, USA). Following lysis of the blood cells, the samples were subjected to centrifugation for $10 \mathrm{~min}$ at $4^{\circ} \mathrm{C}$ at $1,500 \mathrm{rpm}$ to isolate the leukocytes. The leukocytes were cultured on glass coverslips and fixed in $4 \%$ paraformaldehyde for $15 \mathrm{~min}$ at room temperature. Slips were washed in PBS three times for $30 \mathrm{~min}$ at room temperature and incubated with $0.1 \%$ Triton $\mathrm{X}-100$ for $30 \mathrm{~min}$ at room temperature. Following washing, the slips were blocked in goat serum (10\%; Thermo Fisher Scientific, Inc.) for $20 \mathrm{~min}$ at room temperature. The cells were then incubated with anti-CD3 (cat. no. SAB4700040; dilution 1:200), anti-CD19 (cat. no. SAB5500047; dilution 1:200) and anti-CD11b (cat. no. SAB4700386; dilution 1:200; all from Sigma-Aldrich; Merck KGaA, Darsmtdt, Germany) antibodies at $4^{\circ} \mathrm{C}$ overnight. Subsequently, the cells were washed for $15 \mathrm{~min}$ twice with PBS at room temperature and incubated with polyclonal peroxidase-conjugated goat anti-rabbit antibody (cat. no. ZDR-5306; dilution 1:200, ZSGB-BIO) at room temperature for $1 \mathrm{~h}$. The cells were observed under a fluorescence microscope (BX53; Olympus) at x250 magnification. Flow cytometry was used for the analysis of surface markers using the previously reported procedures (21-23).

Determination of biochemical profiles. The level of various components, including serum glutamate pyruvate transaminase (sGPT), serum glutamate oxaloacetic transaminase (sGOT) and blood urea nitrogen (BUN), in the rat blood serum samples was determined using the previously described procedures $(24,25)$.

Statistical analysis. The presented data are the mean \pm standard error of the mean of three experiments performed independently. The data were analyzed using one-way analysis of variance followed by Student-Newman-Keuls test for multiple comparisons. All statistical analyses were performed using SPSS 17.0 software package (SPSS, Inc., Chicago, IL, USA). $\mathrm{P}<0.05$ was considered to indicate a statistically significant difference.

\section{Results}

Benzoxime has an inhibitory effect on RBL-1 cell viability. RBL-1 cells were exposed for $24 \mathrm{~h}$ to a range of benzoxime doses from 2-14 $\mu \mathrm{M}$ and the effect on viability of the cells was examined using an MTT assay. It was observed that an increase in the dosage of benzoxime from 2 to $12 \mu \mathrm{M}$ reduced RBL-1 cell viability from 92 to $21 \%$. Further increase in benzoxime concentration did not significantly decrease the viability inhibition, compared with $12 \mu \mathrm{M}$ benzoxime. The 


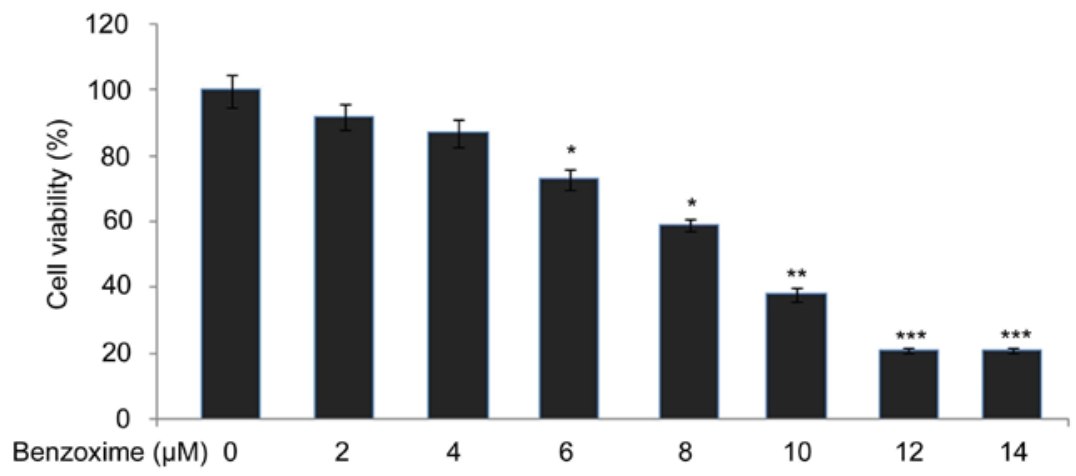

Figure 2. Benzoxime reduces RBL-1 cell viability. Treatment of RBL-1 cells for $24 \mathrm{~h}$ with various concentrations $(2,4,6,8,10,12$ and $14 \mu \mathrm{M})$ of benzoxime was followed by an MTT assay. The data are presented as the mean \pm standard deviation of three independent experiments. ${ }^{*} \mathrm{P}<0.05,{ }^{* * *} \mathrm{P}<0.02,{ }^{* * * *} \mathrm{P}<0.01$ vs. $0 \mu \mathrm{M}$ benzoxime.

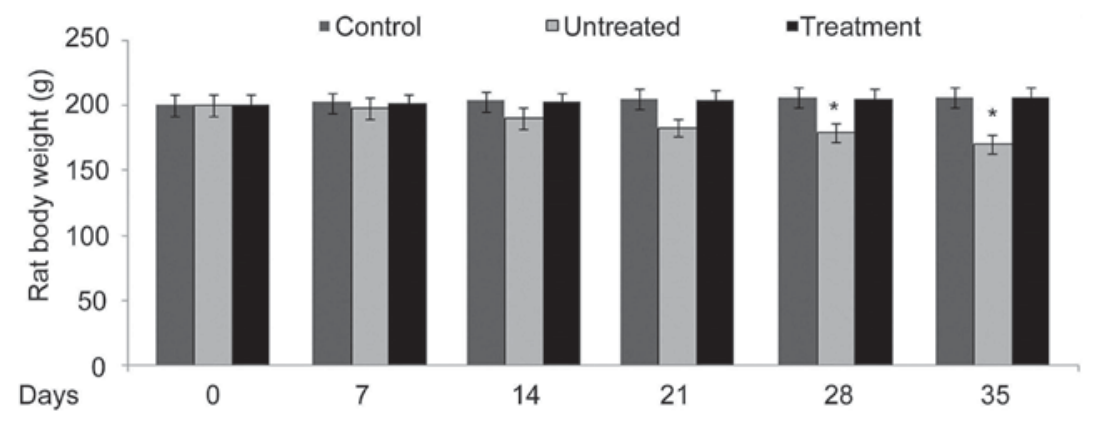

Figure 3. Benzoxime treatment of RBL-1 cell rat allograft model prevents loss of body weight. The body weight presented for each group is the mean \pm standard deviation of all the rats in the group. The weights presented are between the day of implantation and day 35 after implantation of the tumor cells. ${ }^{*} \mathrm{P}<0.05$ vs. negative control and benzoxime treatment group.

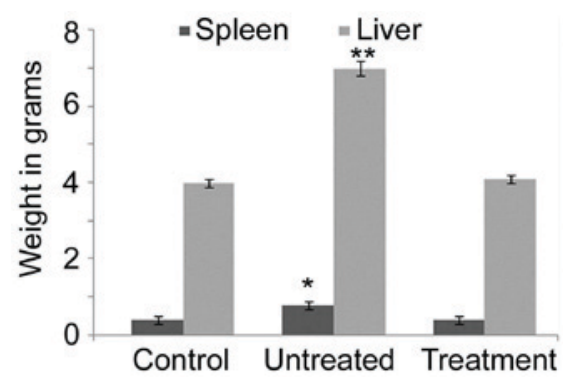

Figure 4. Benzoxime treatment of RBL-1 cell rat allograft model prevents the increase in spleen and liver weight. The expressed data are presented as the mean \pm standard error of the mean of the weight of spleens and livers of all the rats in the group on day 35 following implantation of the tumor cells ${ }^{*} \mathrm{P}<0.05$ and ${ }^{* *} \mathrm{P}<0.02$ vs. negative control group.

viability of the RBL-1 cells following treatment with $14 \mu \mathrm{M}$ benzoxime was determined to be $24 \%$ after $24 \mathrm{~h}$ (Fig. 2).

Development of leukemia in Sprague-Dawley rats is inhibited following treatment with benzoxime. In benzoxime-treated rats, body weight was determined to be similar to that of the rats in the negative control group. Compared with the negative control group rats, the positive control group presented with significantly $(\mathrm{P}<0.05)$ reduced body weight $($ Fig. 3$)$. The weights of the spleen and liver were determined to be significantly increased in the positive control rats compared with those in the negative control and benzoxime-treated groups, after 35 days (Fig. 4). The liver and spleen were also determined to be enlarged in the positive control rats compared with those in the negative control and benzoxime-treated groups, after 35 days (Fig. 5). The average tumor size in the liver of the positive control group was $540 \mathrm{~mm}^{3}$, while no tumor growth was observed in the rats of the negative control and treatment groups. In the spleen of the positive control group, the tumor size was determined to be $435 \mathrm{~mm}^{3}$, but no tumor was present in the rats of the negative control and treatment groups (Fig. 5).

Blood cell surface markers in rats with leukemia are affected by benzoxime. Analysis of leukocytes from positive control rats after 35 days demonstrated a significant increase $(\mathrm{P}<0.05)$ in CD11b and CD45 levels compared with those in negative control rats. The level of leukocyte surface markers CD11b and CD45 was determined to be similar in the rats of the benzoxime treatment and negative control groups (Fig. 6).

Benzoxime treatment prevents alteration in hematological, renal and hepatic parameters in rats with leukemia. Determination of general body weight, and weight of spleen and liver demonstrated no significant changes between rats of the benzoxime treatment and negative control groups. Additionally, analysis of the level of sGPT, sGOT and BUN indicated that all the three components had no significant changes between the rats of the benzoxime treatment and negative control groups. At 35 days, the levels of these three components in rats treated with benzoxime were close to those in the control animals (Fig. 7). These data demonstrated that 


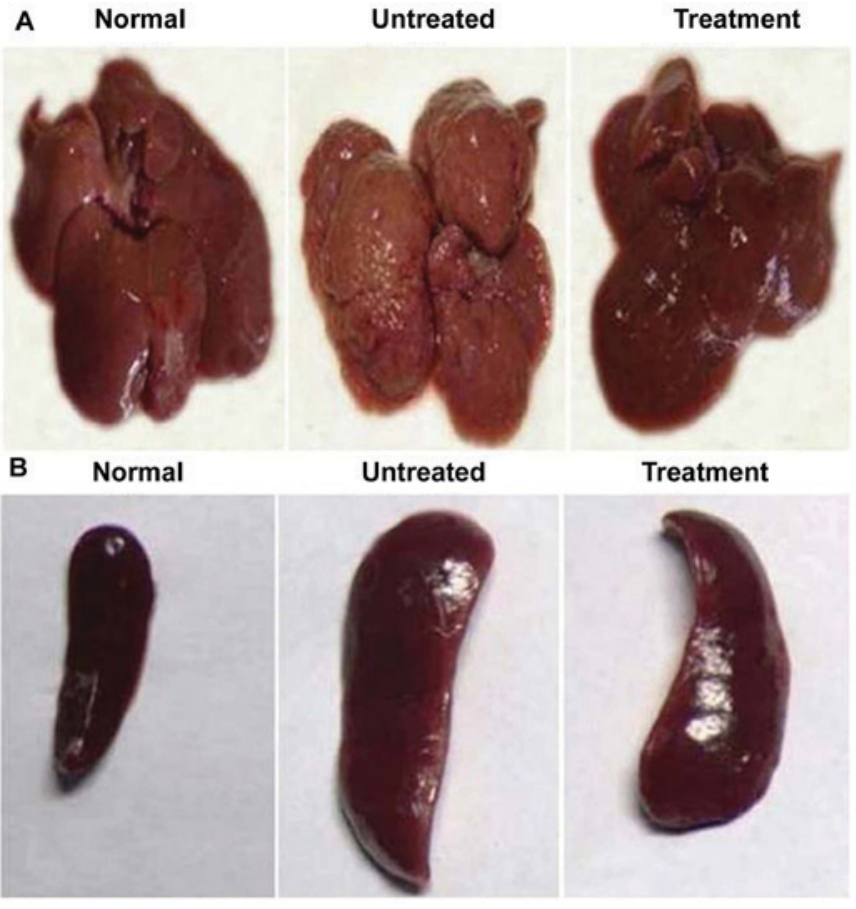

Figure 5. Benzoxime treatment maintains the size of (A) liver and (B) spleen in RBL-1 cell rat allograft models. The livers and spleens of all the rats were extracted on day 35 after implantation of the tumor cells. Images were captured at a magnification of $\mathrm{x} 200$.

the liver and kidneys are not influenced by benzoxime in rats with leukemia.

\section{Discussion}

The present study aimed to investigate the effect of benzoxime on leukemia RBL-1 cell viability in vitro and in RBL-1 cell rat leukemia allograft models in vivo. Upregulation of proliferation and failure to undergo differentiation into hematopoietic cells comprise the characteristic features of leukemia (5-7); therefore, suppression of leukemia cell proliferation is considered to be of notable importance for its treatment. The present study demonstrated that the synthetic compound benzoxime has the potential to inhibit the proliferation of leukemia RBL-1 cells. Benzoxime inhibited the proliferation of RBL-1 cells in a dose-dependent manner without inducing any harmful effects in vivo. These data indicated that benzoxime should be evaluated for its potential as an anti-leukemia agent; thus, an in vivo leukemia rat model was established by transplantation of leukemia RBL-1 cells into Sprague-Dawley rats using the previously reported procedures $(22,23)$. Anti-leukemic studies for the evaluation of various molecules are generally performed using murine allograft models, due to the quick and easy developmental procedures $(26,27)$.

Numerous studies have evaluated the anti-leukemic potential of a number of chemotherapeutic agents such as 2-benzyloxybenzaldehyde, chloroquinine and chrysin; however, leukemia continues to be a challenge for clinicians and researchers $(22,27,28)$. The present study demonstrated that benzoxime has an anti-leukemia effect in leukemia RBL-1 cell rat models in vivo. Benzoxime treatment of the leukemic rat model resulted in the prevention of loss of body weight

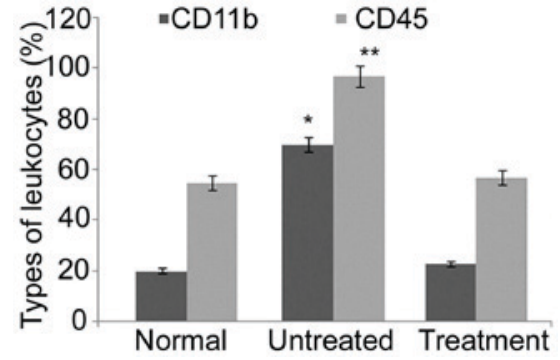

Figure 6. Benzoxime treatment of leukemia Sprague-Dawley rats reduces the expression of cell markers in leukocytes. On day 35 after tumor cell implantation, the blood samples of rats were collected and subjected to flow cytometry for analysis of CD11b and CD45 levels. Expressed data are presented as the mean \pm standard error of the mean of all the rats at day 35 after implantation of the tumor cells. ${ }^{*} \mathrm{P}<0.05$ and ${ }^{* *} \mathrm{P}<0.02$ vs. negative control group. $\mathrm{CD}$, cluster of differentiation.

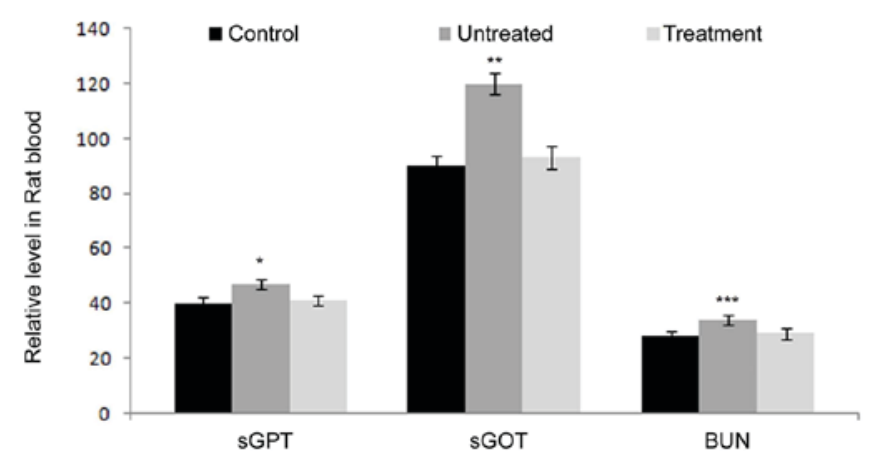

Figure 7. Effect of benzoxime on blood biochemical profile in RBL-1 cell rat leukemia allograft models. The blood samples were collected on day 35 after tumor cell implantation for examination of the biochemical profile. ${ }^{*} \mathrm{P}<0.05$ and ${ }^{* *} \mathrm{P}<0.02$ vs. negative control and treatment group. sGPT (U/1), serum glutamic pyruvic transaminase; sGOT (U/1), serum glutamic oxaloacetic transaminase; BUN (mg/dl), blood urea nitrogen.

compared with the positive control group. The body weight in the positive control rats was significantly reduced compared with the benzoxime treatment and negative control rats. The weight of the liver and spleen was significantly increased in the positive control rats compared with that in the negative control group. It was determined that the level of monocyte surface marker CD11b and CD45 in the positive control rats was significantly increased compared with that in the negative control group; however, a significant increase in the level of CD11b was prevented by the treatment of leukemia rats with benzoxime.

In conclusion, the present study demonstrated that benzoxime reduces leukemia RBL-1 cell proliferation in vitro without causing any harmful effects in vivo. It also prevented damage to the spleen and liver, and changes in SGPT, sGOT and BUN. Thus, the present study demonstrated that benzoxime acts as a potential candidate for the treatment of leukemia. However, further experiments need to be performed to confirm these results.

\section{Acknowledgements}

Not applicable.

\section{Funding}

No funding was received. 


\section{Availability of data and materials}

The datasets used and/or analyzed during the current study are available from the corresponding author on reasonable request.

\section{Authors' contributions}

YL designed the study and wrote the paper. HW, RZ and GZ conducted the experiments. YY and ZL performed the literature study and compiled the data. All the authors wrote and approved the article for publication.

\section{Ethics approval and consent to participate}

The working protocols involving animals were approved by the Committee for Care and Use of Animal of Guangzhou University of Traditional Chinese Medicine (approval no. 2014A123).

\section{Patient consent for publication}

Not applicable.

\section{Competing interests}

The authors declare that they have no conflict of interest.

\section{References}

1. Liu YQ, Zhao FJ, Chen WQ, et al: An analysis of incidence and mortality of leukemia in China, 2009. China Cancer 7: 528-534, 2013.

2. ESPíRITO Santo AE, Chacim S, Ferreira I, Leite L, Moreira C, Pereira D, Dantas Brito MD, Nunes M, Domingues N, Oliveira I, et al: Effect of therapy-related acute myeloid leukemia on the outcome of patients with acute myeloid leukemia. Oncol Lett 12: 262-268, 2016.

3. Li WX, Li YK and Lin HT: Correlation between survivin polymorphism and acute leukemia of children. Expt Ther Med 15: 2941-2945, 2018

4. Jiang KL, Ma PP, Yang XQ, Zhong L, Wang H, Zhu XY and Liu BZ: Neutrophil elastase and its therapeutic effect on leukemia cells. Mol Med Rep 12: 4165-4172, 2015.

5. Yildirim R, Gundogdu M, Ozbicer A, Kiki I, Erdem F and Dogan H: Acute promyelocytic leukemia, centre, experience, Turkey. Transfus Apher Sci 48: 45-49, 2013.

6. Guo J, Chang CK and Li X: Recent advances of molecular mechanisms influencing prognosis of myelodysplastic syndrome-review. Zhongguo Shi Yan Xue Ye Xue Za Zhi 20 1020-1024, 2012 (In Chinese).

7. Kinoshita K and Funauchi M: Therapeutic effect of retinoic acid in lupus nephritis. Nihon Rinsho Meneki Gakkai Kaishi 35: 1-7, 2012 (In Japanese).

8. Flatt T, Neville K, Lewing K and Dalal J: Successful treatment of fanconi anemia and T-cell acute lymphoblastic leukemia. Case Report Hematol 2012: 396395, 2012.

9. Estey EH: Acute myeloid leukemia: 2012 update on diagnosis, risk stratification, and management. Am J Hematol 87: 89-99, 2012.

10. Wang TT and Chen BA: Leukemia stem/progenitor cells and target therapy for leukemia-review. Zhongguo Shi Yan Xue Ye Xue Za Zhi 18: 1654-1658, 2010 (In Chinese).

11. Zhai YK, Pan YL, Niu YB, Li CR, Wu XL, Fan WT, Lu TL, Mei QB and Xian CJ: The importance of the prenyl group in the activities of osthole in enhancing bone formation and inhibiting bone resorption in vitro. Int J Endocrinol 2014: 921954, 2014.
12. Yogesh HS, Chandrashekhar VM, Katti HR, Ganapaty S, Raghavendra HL, Gowda GK and Goplakhrishna B: Anti-osteoporotic activity of aqueous-methanol extract of Berberis aristata in ovariectomized rats. J Ethnopharmacol 134: 334-338, 2011.

13. Lee WS, Lee EG, Sung MS and Yoo WH: Kaempferol inhibits IL-1 $\beta$-stimulated, RANKL-mediated osteoclastogenesis via downregulation of MAPKs, c-Fos, and NFATc1.Inflammation 37: 1221-1230, 2014.

14. Tyagi AM, Srivastava K, Singh AK, Kumar A, Changkija B, Pandey R, Lahiri S, Nagar GK, Yadav DK, Maurya R, et al: Formononetin reverses established osteopenia in adult ovariectomized rats. Menopause 19: 856-863, 2012.

15. Ates O, Cayli S, Altinoz E, Gurses I, Yucel N, Sener M, Kocak A and Yologlu S: Neuroprotection by resveratrol against traumatic brain injury in rats. Mol Cell Biochem 294: 137-144, 2007.

16. Gatson JW, Liu MM, Abdelfattah K, Wigginton JG, Smith S, Wolf S and Minei JP: Resveratrol decreases inflammation in the brain of mice with mild traumatic brain injury. J Trauma Acute Care Surg 74: 470-475, 2013.

17. Lin CJ, Chen TH, Yang LY and Shih CM: Resveratrol protects astrocytes against traumatic brain injury through inhibiting apoptotic and autophagic cell death. Cell Death Dis 5: e1147, 2014.

18. Lin C, Yang JS, Tsai SC, Lin CF and Lee MR: In vivo evaluation of the synthesized novel 2-benzyloxybenzaldehyde analog CCY-1a-E2 for the treatment of leukemia in the BALB/c mouse WEHI-3 allograft model. Oncol Lett 5: 777-782, 2013.

19. Alayev A, Sun Y, Snyder RB, Berger SM, Yu JJ and Holz MK: Resveratrol prevents rapamycin-induced upregulation of autophagy and selectively induces apoptosis in TSC2-deficient cells. Cell Cycle 13: 371-382, 2014.

20. Li H, Zhai Z, Liu G, Tang T, Lin Z, Zheng M, Qin A and Dai K: Sanguinarine inhibits osteoclast formation and bone resorption via suppressing RANKL-induced activation of NF- $\kappa B$ and ERK signaling pathways. Biochem Biophys Res Commun 430: 951-956, 2013.

21. Mackraj I, Govender T and Gathiram P: Sanguinarine. Cardiovasc Ther 26: 75-83, 2008.

22. Chung JG, Yang JS, Huang LJ, Lee FY, Teng CM, Tsai SC, Lin KL, Wang SF and Kuo SC: Proteomic approach to studying the cytotoxicity of YC-1 on U937 leukemia cells and antileukemia activity in orthotopic model of leukemia mice. Proteomics 7: 3305-3317, 2007.

23. Lu CC, Yang JS, Chiang JH, Hour MJ, Lin KL, Lin JJ, Huang WW, Tsuzuki M, Lee TH and Chung JG: Novel quinazolinone MJ-29 triggers endoplasmic reticulum stress and intrinsic apoptosis in murine leukemia WEHI-3 cells and inhibits leukemic mice. PLoS One 7: e36831, 2012.

24. Chiang JH, Yang JS, Ma CY, Yang MD, Huang HY, Hsia TC, Kuo HM, Wu PP, Lee TH and Chung JG: Danthron, an anthraquinone derivative, induces DNA damage and caspase cascades-mediated apoptosis in SNU-1 human gastric cancer cells through mitochondrial permeability transition pores and Bax-triggered pathways. Chem Res Toxicol 24: 20-29, 2011.

25. Hsu SC, Ou CC, Li JW, Chuang TC, Kuo HP, Liu JY, Chen CS, Lin SC, Su CH and Kao MC: Ganoderma tsugae extracts inhibit colorectal cancer cell growth via $\mathrm{G}(2) / \mathrm{M}$ cell cycle arrest. J Ethnopharmacol 120: 394-401, 2008.

26. Yang JS, Wu CC, Kuo CL, Lan YH, Yeh CC, Yu CC, Lien JC, Hsu YM, Kuo WW, Wood WG, et al: Solanum lyratum extracts induce extrinsic and intrinsic pathways of apoptosis in WEHI-3 murine leukemia cells and inhibit allograft tumor. Evid Based Complement Alternat Med 2012: 254960, 2012.

27. Li J and Sartorelli AC: Synergistic induction of the differentiation of WEHI-3B D+ myelomonocytic leukemia cells by retinoic acid and granulocyte colony-stimulating factor. Leuk Res 16: 571-576, 1992.

28. Barr RD and Harnish D: Induction of differentiation of HL-60 and WEHI-3B D+ leukemia cells by lithium chloride. Leuk Res 17: 1017-1018, 1993. 